\title{
Comparative Examination of the Therapeutic Deficiency of Oral Metronidazole Plus Prangos ferulacea Vaginal Cream Versus Oral Metronidazole Plus Placebo Vaginal Cream in Accelerating Trichomonas Vaginalis Infection Recovery: A Triple-Blind Clinical Trial
}

\author{
Asieh Azadpour Motlagh ${ }^{\circledR}$, Mahrokh Dolatian $^{2 *}$, Faraz Mojab ${ }^{3}$, Malihe Nasiri ${ }^{4}$, Behrouz Ezatpour $^{5}$, \\ Nasibeh Sharifi ${ }^{6}$, Narjes Feizollahi ${ }^{7}$, Zohreh Mahmoodi ${ }^{8}$
}

\begin{abstract}
Objectives: Trichomonas infection is prevalent in the United States and a metronidazole oral tablet is the medication of choice for treating this infection. Based on various side-effects of oral or vaginal metronidazole and the increase in microbial resistance against chemical antibiotics, the use of herbal medicine with fewer side-effects seems to be essential. Laboratory experiments indicate the strong anti-microbial effects of Prangos ferulacea (PF) medicinal herb. However, no clinical trial has focused on its anti-microbial effects in humans. Thus, the present study aimed to determine the effects of PF vaginal cream on accelerating Trichomonas vaginalis infection (TVI) recovery.

Materials and Methods: The present randomized clinical trial was conducted on 80 non-pregnant women visiting the healthcare centers affiliated with Lorestan University of Medical Sciences, Iran, in 2018. Trichomonas infection was diagnosed based on patient complaints, clinical observations, as well as wet mount and stained microscopic tests. The women were randomly divided into two groups of 40 each. One group received oral metronidazole plus PF vaginal cream while the other received oral metronidazole plus placebo vaginal cream for 7 days. Clinical observations, along with wet mount and stained microscopic tests were performed during 7 days following the treatment. Finally, data were analyzed using independent-samples $t$ test, as well as chi-square, Fisher exact, Mann-Whitney $\mathrm{U}$, and McNemar tests at the significance level of $P<0.05$.

Results: Based on the results, the response to treatment with oral metronidazole plus PF vaginal cream was 92.50 based on patient complaints. More precisely, $86.25 \%$ was based on clinical criteria (i.e., strawberry cervix, foamy greenish-yellow vaginal discharge, $\mathrm{pH} \geq 4.5$, and positive amine test) and $85 \%$ was related to the microscopic criteria of wet mount ( $\mathrm{x} 40)$ and polymorphonuclear leukocytes (x100). In addition, the response to treatment with oral metronidazole and placebo vaginal cream was $91.25 \%, 83.12 \%$, and $80 \%$ based on the patient complaint, clinical criteria, and microscopic criteria, respectively. Eventually, the analysis of the patient complaint, clinical criteria, and microscopic criteria in each group revealed a significant difference before and after the treatment $(P<0.001)$

Conclusions: The results of this study showed that the PF herbal vaginal cream can be used for the treatment of TVI as an effective treatment along with oral metronidazole.

Keywords: Prangos ferulacea, Trichomonas vaginalis, Treatment, Metronidazole
\end{abstract}

\section{Introduction}

Trichomonas infection results from a parasitic protozoan called Trichomonas vaginalis, which is considered as a prevalent infection in the United States (1).

The clinical manifestations of this infection have varying severity, ranging from mild burning to severe inflammation, vaginal odor, and light, white, yellow, or green discharge. Vaginal discharge shows a $\mathrm{pH}$ increase from 5 to 6 . Women often experience vaginal itching, burning, burning sensation while urinating, abdominal pain, vulva redness or pain, cervical discharge, and strawberry cervix (2). Some complications related to Trichomonas vaginalis infection (TVI) include infertility, cervical cancer, the increased risk of infection with human immunodeficiency virus (HIV), post-hysterectomy cellulitis, and other sexually transmitted infections (3). A

Received 15 June 2019, Accepted 17 September 2019, Available online 6 October 2019

${ }^{1}$ Department of Midwifery and Reproductive Health, School of Nursing and Midwifery, Tehran, Iran. ${ }^{2}$ Midwifery and Reproductive Health Research Center, Department of Midwifery and Reproductive Health, School of Nursing and Midwifery, Shahid Beheshti University of Medical Sciences, Tehran, Iran. ${ }^{3}$ Department of Pharmacognosy, School of Pharmacy, Shahid Beheshti University of Medical Sciences, Tehran, Iran. ${ }^{4}$ Department of Paramedical, School of Nursing and Midwifery, Shahid Beheshti University of Medical Sciences, Tehran, Iran. ${ }^{5}$ Razi Herbal Medicines Research Center, Lorestan University of Medical Sciences, Lorestan, Iran. ${ }^{6}$ Department of Midwifery, School of Nursing and Midwifery, Ilam University of Medical Sciences, Ilam, Iran. ${ }^{7}$ School of Medicine, Tehran University of Medical Sciences, Tehran, Iran. ${ }^{8}$ Social Determinants of Health Research Center, Alborz University of Medical Sciences, Karaj, Iran.

*Corresponding Author: Mahrokh Dolatian, Tel: (+98) 9123848716, Email: mhdolatian@gmail.com 
significant correlation exists between TVI and low birth at weight, prematurity, as well as the rupture of membranes and preterm birth. Diagnostic methods available for Trichomonas include wet mount, Giemsa stain, culture in a laboratory environment, cellular culture, and molecular methods (3). Trichomonas infection is easily diagnosed by viewing the motile Trichomonas under a microscope on the wet slide after adding a drop of the saline solution on vaginal discharge. Physicians perform this test in their clinic immediately after sampling due to the loss of viable organisms. The metronidazole oral tablet is the medication of choice for treating this infection. This tablet has digestive side-effects and skin rashes and may cause vertigo, seizures, peripheral neuropathy, along with metallic taste in the mouth, dry mouth, insomnia, and drowsiness upon passing the blood-brain barrier (2). Trichomonas resistance to metronidazole is confirmed as well. Clindamycin is a lincosamide anti-biotic introduced by the US Food and Drug Administration and is appropriate for treating anaerobic infections. Due to its oil base, clindamycin may weaken the latex of the condom and diaphragm used as a contraceptive. The use of these products is not recommended within 72 hours after treatment with clindamycin suppository or cream. Its major weak point is the tendency for causing antibioticrelated diarrhea including severe clostridium colitis. In general, diarrhea and allergic reactions are considered as its most common side-effects. The level of resistance of bacteria and parasites to clindamycin has increased over time in the US (4).

Currently, herbal medications have received special attention as an alternative for chemical drugs in the treatment of infections $(5,6)$. In relation to the complementary and alternative treatment of T. vaginitis, Salvia officinalis and Menthe piperita had efficient effect against $T$. vaginalis growth in culture medium and so these two herbs can be considered as alternatives drugs. However, further investigations are recommended (7).

Prangos ferulacea (PF) is one such herb with antibacterial and anti-viral properties, which is a herb used in Iranian traditional medicine (8). This plant has a yellow and saffron-like gum extracted from its root and stem (9). In traditional medicine, PF was used for treating digestive problems, joint inflammation, vascular obstruction, bleeding, and vaginal itching and infection, countering toxins in addition to curing uterine infections and removing stillborn fetuses $(10,11)$.

Considering the side-effects of Trichomonas infection, microbial resistance against chemical drugs in recent years, and the acceptance of medicinal herbs and traditional medications, the present controlled randomized clinical trial examined the effect of PF vaginal cream on accelerating Trichomonas infection recovery.

\section{Materials and Methods}

The present triple-blind randomized controlled clinical trial was conducted in clinics affiliated with Lorestan University of Medical Sciences upon the approval of the Ethics Committee of Shahid Beheshti University of Medical Sciences, Tehran, from late May to late November 2017. The population comprised women visiting the noted clinics. In addition, research units included nonpregnant women aged 15 to 49 years who were married, non-breast feeding, and non-menopausal, complained of vaginal discharge, had regular menstrual cycles. Further, they were not infected with other types of vaginitis, took no vaginal medications or antibiotics in the past 2 weeks, did not participate in other research studies in the past 4 weeks, had no cervical problems or abnormalities or any chronic diseases, and showed willingness to participate in the present study by giving written informed consent. At any stage of the study, they were excluded due to demonstrating unwillingness for participation, forgetting to take the medication for one night, having sexual intercourse, becoming pregnant, having menstrual bleeding, or failing to visit on time.

The double ratio estimate formula was employed to determine the sample size. Assuming $\alpha=0.05$ and $\beta=0.8$,

$$
\begin{aligned}
& n=\left[\frac{Z_{\alpha / 2} \sqrt{2 \bar{p}(1-\bar{p})}+Z_{\beta} \sqrt{p_{1}\left(1-p_{1}\right)+p_{2}\left(1-p_{2}\right)}}{p_{1}-p_{2}}\right]^{2} \\
& \bar{p}=\left(p_{1}+p_{2}\right) / 2 \\
& \mathrm{p} 1=0.70 \\
& \mathrm{p} 2=0.90 \\
& \alpha=0.05 \rightarrow \mathrm{Z} \alpha=1.96 \\
& 1-\beta=0.80 \rightarrow \mathrm{Z} \beta=0.85 \\
& \mathrm{~N}=40 \\
& \mathrm{P} 1: \text { Therapeutic efficiency of metronidazole }
\end{aligned}
$$

p2: Therapeutic efficiency of Pseudomonas fluorescens lectin

a: Type 1 error probability

$\beta$ : Type II error probability

Thus, 45 cases were considered per group by assuming sample attrition. The findings of this study were based on the objectives and hypothesis of the research and the data were analyzed by using descriptive (i.e., mean, standard deviation, frequency, and percent) and inferential (i.e., independent $t$ test, as well as chi-square, Fisher exact, Mann-Whitney, and McNamar tests) statistics by SPSS software, version 20 .

\section{Inclusion Criteria}

1. 1. Non-pregnant, non-lactating, and non-smoker married women aged 15 to 49 years;

2. 2. A desire for participation in the research;

3. 3. Mainly complaining of the green discharge, foamy;

4. 4. Lack of the menstrual period in the next fourteen days;

5. 5. Unavailability of abnormal vaginal bleeding during the course of treatment; 
6. Lack of intercourse during the course of treatment;

7. No use of the cream, suppository, and vaginal shower during the last week, during treatment, and one week thereafter;

8. Lack of chronic medical conditions (e.g., heart, kidney, diabetes, arthritis, and the like);

9. Absence of a history of organ transplantation (kidneyliver and the like);

10. Lack of the use of broad-spectrum antibiotics, hormonal agents, anticoagulant, and suppressor drugs;

11. Absence of other vaginal infections;

12. No history of susceptibility to metronidazole or topical drugs;

13. Reading and writing literacy.

\section{Exclusion Criteria}

1. Unwillingness to continue participating in the study;

2. No referral for follow-up on prescribed days;

3. Lack of using vaginal cream for two consecutive days;

4. Allergy to PF vaginal cream or metronidazole or intolerance to either form of the drug;

5. Engagement in intercourse during treatment;

6. Presence of vaginal bleeding or menstruation during the course of treatment and one week thereafter;

7. Presence of a vaginal infection (Candida or Vaginosis bacterial);

8. Pregnancy occurrence during treatment and follow up;

9. Not completing the questionnaires.

The studied population comprised 3357 women visiting the mentioned clinics. Of these, 1245 (37.08\%) cases did not have abnormal vaginal discharge. Of the remaining 2112 women $(62.92 \%)$ with abnormal vaginal discharge, 282 (13.35\%), 475 (22.49\%), 1021 (48.34\%), and 334 (15.81\%) had cervicitis, trichomoniasis, yeast infection, and vaginobacterial infection, respectively. Then, from among eligible women, 90 cases were selected and randomly assigned to two groups of 45 .

Of the initial population, 250 and 110 women were excluded due to the lack of meeting the inclusion criteria and giving consent. Further, 25 cases were removed due to other reasons. Finally, 90 women participated in the study. In each group, 5 cases were excluded in the second stage of visiting (Figure 1).

In this study, 90 women with one partner infected with TVI complaining of vaginal discharge, burning, itching, tenderness, and abdominal pain who met the inclusion criteria were selected through the convenience purposive sampling technique. To collect the required data, the researcher visited the studied clinics, introduced herself, received the approval of the directors of centers,

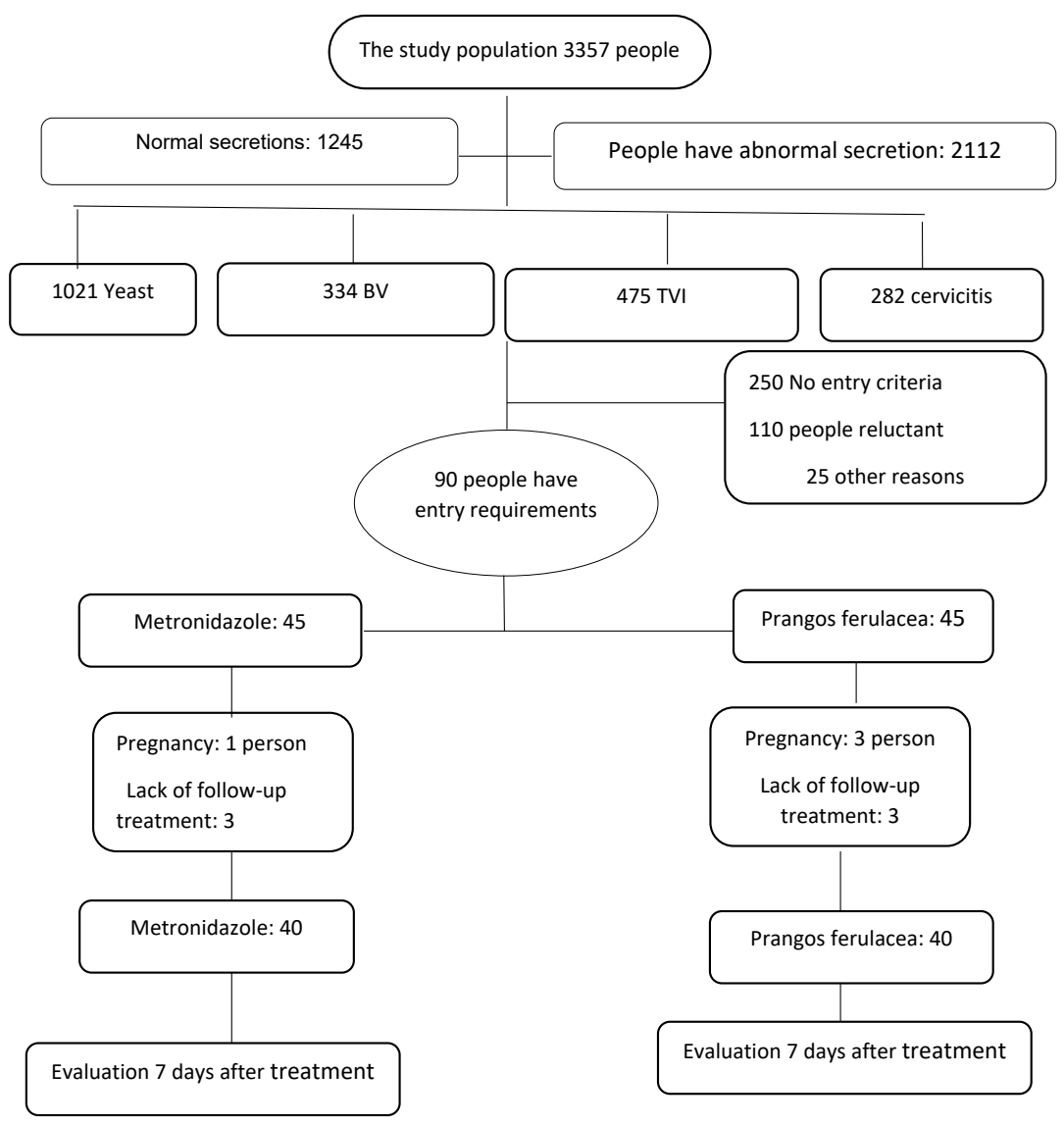

Figure 1. Participants in the Research. 
and performed preliminary interviews with patients, followed by informing them about the study objectives and confidentiality of data and then selecting eligible participants. Furthermore, the applied checklist tapped into complaints, as well as demographic and gynecological information of patients. The other checklist was used for direction observation (i.e., strawberry cervix and foamy greenish-yellow vaginal discharge) during physical examination. In addition, a checklist for measuring vaginal $\mathrm{pH}$, whiff test, wet mount, and the microscopic viewing of polymorphonuclear leukocytes in stained slides was completed as follows. The patient was placed in the lithotomy position. First, the nature of discharge and symptoms were directly examined using a disposable speculum with no lubricant. Then, the samples were taken from the discharge on the lateral vaginal walls by using a sterile cotton swab smeared with sterile physiological saline solution. Next, the whiff test was performed by adding some drops of $10 \%$ potassium hydroxide solution on the discharge of the first slide taken with the sterile cotton swab. Upon smelling a fishy odor, the test was considered positive, otherwise, it was negative. Afterward, the sample discharge was taken with a second swab and smeared on the paper $\mathrm{pH}$ meter. After discoloration, the level of $\mathrm{pH}$ was determined by comparing the resulting color with the colored page printed on the box of $\mathrm{pH}$ meter. Additionally, the third sample was taken from the discharge on lateral vaginal walls with a third sterile cotton swab and smeared on the slide if the vaginal $\mathrm{pH}$ ranged between 5 and 6 . Then, a drop of physiological solution was added to the sample and it was immediately viewed under a microscope with the magnification of $\times 40$. The sexual TVI was diagnosed if motile pearl-shaped trophozoite were present in the wet smear. The wet mount is a simple microscopic test. Still, it is necessary to perform the examination within 10 minutes of sampling because the effectiveness of the test decreases thereafter (12). Moreover, a fourth sample was prepared using the noted method in order to confirm this diagnostic test. After drying at room temperature and fixing the sample with the heat of an alcohol burner or by covering the slide by a few drops of methanol, Giemsa staining was performed for the final confirmation of the pear-shaped morphologic of Trichomonas vaginalis and polymorphonuclear. It was then sent to the specialized laboratory of Razi Research Center. The microbiologist smeared a drop of the immersion oil on the slide and examined the slide under microscopy at the magnification of $\times 100$. Then, the researcher completed the previously developed checklist, including direct observations during the physical examination, main complaints of the patients, the sampling and preparation of slides for Giemsa staining and its microscopic examination, the $\mathrm{pH}$ of vaginal discharge, and the whiff test. If the patients were supposed to be treated only based on clinical diagnosis, the majority of infected women would be left untreated or some uninfected women would receive treatment without needing it. Thus, the diagnosis of trichomoniasis must be performed with the help of clinical and microbiological tests. The medications were administered as follows:

Some cards were placed in a box, A and B were written on an equal number of them, corresponding to the code of placebo or PF vaginal cream. It is noteworthy that the researcher was blind to the content of the creams. The patients randomly chose a card from the box and received the medication based on the letter typed on the card. It must be noted that both groups received the metronidazole tablet equally and they were asked to visit one week after all the medications were taken to examine their recovery. On the second visit, the same process of the first visit was repeated and the recovered patients were informed of their recovery via telephone. If the response to treatment was negative, they were referred for further treatments.

The data collection instrument included a demographic questionnaire, which was a therapeutic checklist for examining the pre- and post-intervention differences based on patient complaints, the $\mathrm{pH}$ of vaginal discharge, whiff test, and wet mount based on microscopic criteria and Giemsa staining, and the side-effects of medications.

\section{Results}

In this study, 90 married women were randomly divided into two groups of 45 . After visiting the sampling setting, 4 and 6 women were excluded as they had become pregnant and did not visit for follow-up, respectively. In total, 80 women (40 per group) with the mean age of $27.81 \pm 7.53$ years participated in this study. The results showed that there was no significant difference between the two groups in terms of demographic characteristics and midwifery variables (Tables 1-3).

Chi-square and Fisher exact tests before treatment indicated that all women in the PF plus metronidazole group experienced itching, burning, vaginal discharge, along with abdominal tenderness and pain. In general, 95\% of patients in each group complained of excessive discharge. In addition, two-thirds and one-fourth cases were related to burning and itching, as well as abdominal tenderness and pain, respectively. Table 4 presents these complains and changes in women after treatment. Based on our clinical observations, about half of the patients in each group suffered from vaginitis and strawberry cervix before treatment. The foamy greenish-yellow discharge was observed in $90 \%$ and $85 \%$ of cases in the PF and metronidazole groups, respectively. Moreover, $100 \%$ of participants in both groups had a pH of $>4.5$ and $40 \%$ had a positive whiff test.

Furthermore, $100 \%$ of patients in the PF plus metronidazole group had motile trophozoites in the direct observation of the wet mount sample under a microscope at the magnification of $\times 40$. In addition, $100 \%$ of patients had polymorphonuclear leukocytes in the microscopic observation at the magnification of $\times 100$ before treatment. 
Table 1. Demographic Characteristics of the Participants

\begin{tabular}{|c|c|c|c|c|c|}
\hline & & & \multicolumn{2}{|l|}{ Groups } & \multirow{3}{*}{$P$ Value } \\
\hline \multirow{2}{*}{\multicolumn{3}{|c|}{ Variable }} & $\begin{array}{l}\text { Metronidazole and Prangos ferulacea } \\
\qquad n=40\end{array}$ & $\begin{array}{l}\text { Metronidazole } \\
n=40\end{array}$ & \\
\hline & & & No. (\%) & No. (\%) & \\
\hline \multicolumn{3}{|c|}{ Age (years), Mean $\pm S D$} & $28.00 \pm 7.80$ & $27.62 \pm 7.35$ & 0.826 \\
\hline \multicolumn{3}{|c|}{ Age at first menstruation, Mean \pm SD } & $12.70 \pm 1.01$ & $12.47 \pm 0.846$ & 0.381 \\
\hline \multicolumn{3}{|c|}{ Age at first pregnancy, Mean \pm SD } & $19.64 \pm 3.63$ & $20.43 \pm 4.05$ & 0.751 \\
\hline \multirow{6}{*}{ Education } & \multirow{3}{*}{ Patient } & A primary school and school & $21(52)$ & $16(40)$ & \multirow{3}{*}{0.286} \\
\hline & & High school & $4(10)$ & $5(12)$ & \\
\hline & & Diploma & $15(37.5)$ & $19(47.5)$ & \\
\hline & \multirow{3}{*}{ Husband } & A primary school and school & $12(30)$ & $16(40)$ & \multirow{3}{*}{0.242} \\
\hline & & High school & $29(58)$ & $32(64)$ & \\
\hline & & Diploma & $19(47.5)$ & $19(47.5)$ & \\
\hline \multirow{6}{*}{ Profession } & \multirow{2}{*}{ Patient } & Housekeeper & $34(85)$ & $33(82.5)$ & \multirow{2}{*}{0.762} \\
\hline & & Employee & $6(15)$ & $7(17.5)$ & \\
\hline & \multirow{4}{*}{ Husband } & Unemployed & $3(7)$ & $2(5)$ & \multirow{4}{*}{0.190} \\
\hline & & Worker & $9(22)$ & $12(30)$ & \\
\hline & & Employee & $11(27)$ & $14(35)$ & \\
\hline & & Free & $17(42)$ & $12(30)$ & \\
\hline
\end{tabular}

Table 2. Health Care Variables

\begin{tabular}{|c|c|c|c|c|}
\hline \multirow[b]{2}{*}{ Variable } & & \multicolumn{2}{|c|}{ Group } & \multirow[b]{2}{*}{$P$ Value } \\
\hline & & $\begin{array}{l}\text { Metronidazole and Prangos } \\
\text { ferulacea } \mathrm{n}=40\end{array}$ & $\begin{array}{c}\text { Metronidazole } \\
n=40\end{array}$ & \\
\hline \multirow{3}{*}{ Having pregnancy } & & & & \multirow{3}{*}{1.000} \\
\hline & Yes & $35(78.5)$ & $35(78.5)$ & \\
\hline & No & $5(12.5)$ & $5(12.5)$ & \\
\hline \multirow{3}{*}{ Type of delivery } & Without childbirth & $5(12.5)$ & $5(12.5)$ & \multirow{3}{*}{0.160} \\
\hline & Vaginal & $30(70)$ & $22(55)$ & \\
\hline & Cesarean & $5(12.5)$ & $13(32.5)$ & \\
\hline \multirow{4}{*}{$\begin{array}{l}\text { The frequency of } \\
\text { sex per week }\end{array}$} & Once a week & $7(17.5)$ & $11(27.50)$ & \multirow{4}{*}{0.482} \\
\hline & Twice a week & $7(17.50)$ & $7(17.50)$ & \\
\hline & Three times a week & $25(62.5)$ & $19(47.5)$ & \\
\hline & Four or more times a week & $1(2.5)$ & $3(3.50)$ & \\
\hline \multirow{3}{*}{ Housing situation } & Personal & $21(52.5)$ & $24(60)$ & \multirow{3}{*}{0.133} \\
\hline & Leased & $12(30)$ & $14(35)$ & \\
\hline & With relatives & $7(17.5)$ & $2(5)$ & \\
\hline \multirow{4}{*}{$\begin{array}{l}\text { The method of } \\
\text { contraception }\end{array}$} & Discontinues & $13(32.5)$ & $8(20)$ & \multirow{4}{*}{0.378} \\
\hline & Oral tablets & $13(32.5)$ & $12(30)$ & \\
\hline & IUD & $7(17.5)$ & $7(17.5)$ & \\
\hline & No way & $7(17.5)$ & $13(32.5)$ & \\
\hline
\end{tabular}

Note. IUD: Intrauterine device.

The related data regarding these changes in patients after treatment are provided in Table 5. The analysis of patient complaints, clinical criteria, and microscopic criteria demonstrated a significant difference in each group before and after treatment based on McNemar test (Table 6).

On average, the first day of the 7 days of the intervention period on which the symptoms decreased, was $2.67 \pm 0.997$ and $3.90 \pm 0.810$ days in PF and metronidazole groups, indicating a significant difference between the two groups based on independent samples $t$ test $(P<0.001)$. In other words, the results of Mann-Whitney $U$ test indicated that about $50 \%$ of patients in the metronidazole plus PF group showed reduced symptoms on the second and third days while over $50 \%$ of them in the metronidazole group experienced this on the third and fourth days, showing a significant difference $(P<0.001)$. The frequency distribution of the day of full recovery during the 7 days of treatment revealed that the mean day of full recovery 
Table 3. Midwifery Variables

\begin{tabular}{|c|c|c|c|c|}
\hline \multirow[b]{2}{*}{ Variable } & & \multicolumn{2}{|c|}{ Group } & \multirow{3}{*}{$P$ Value } \\
\hline & & \multirow{2}{*}{$\begin{array}{c}\text { Metronidazole and Prangos } \\
\text { ferulacea, } \mathrm{n}=40 \\
\text { No. (\%) }\end{array}$} & \multirow{2}{*}{$\begin{array}{c}\text { Metronidazole, } n=40 \\
\text { No. (\%) }\end{array}$} & \\
\hline \multirow{3}{*}{ Drying the perinea } & & & & \\
\hline & Makes dry & $7(17.50)$ & $13(32.50)$ & \multirow{2}{*}{0.121} \\
\hline & Does not dry & $33(82.50)$ & $27(67.50)$ & \\
\hline \multirow{2}{*}{$\begin{array}{l}\text { Histology of using vaginal } \\
\text { shower }\end{array}$} & Yes & $25(62.50)$ & $27(67.50)$ & \multirow{2}{*}{0.639} \\
\hline & No & $15(37.50)$ & $13(32.50)$ & \\
\hline \multirow{2}{*}{ Type of vaginal shower } & lodine & $14(35)$ & $17(42.50)$ & \multirow{2}{*}{0.786} \\
\hline & Vinegar & $11(27.50)$ & $10(25)$ & \\
\hline \multirow{2}{*}{ History of vaginitis } & Yes & $34(85)$ & $34(85)$ & \multirow{2}{*}{1.000} \\
\hline & No & $6(15)$ & $6(15)$ & \\
\hline \multirow{3}{*}{ Number of visits } & One to two times & $16(40)$ & $20(50)$ & \multirow{3}{*}{0.262} \\
\hline & Three to four times & $14(35)$ & $14(35)$ & \\
\hline & More than four times & $10(25)$ & $6(15)$ & \\
\hline \multicolumn{2}{|c|}{ Age of first sexual activity (Mean $\pm S D$ ) } & $17.80 \pm 6.71$ & $17.17 \pm 7.35$ & 0.735 \\
\hline
\end{tabular}

Note. SD: Standard deviation.

Table 4. Complication in the Metronidazole Group and Prangos ferulacea

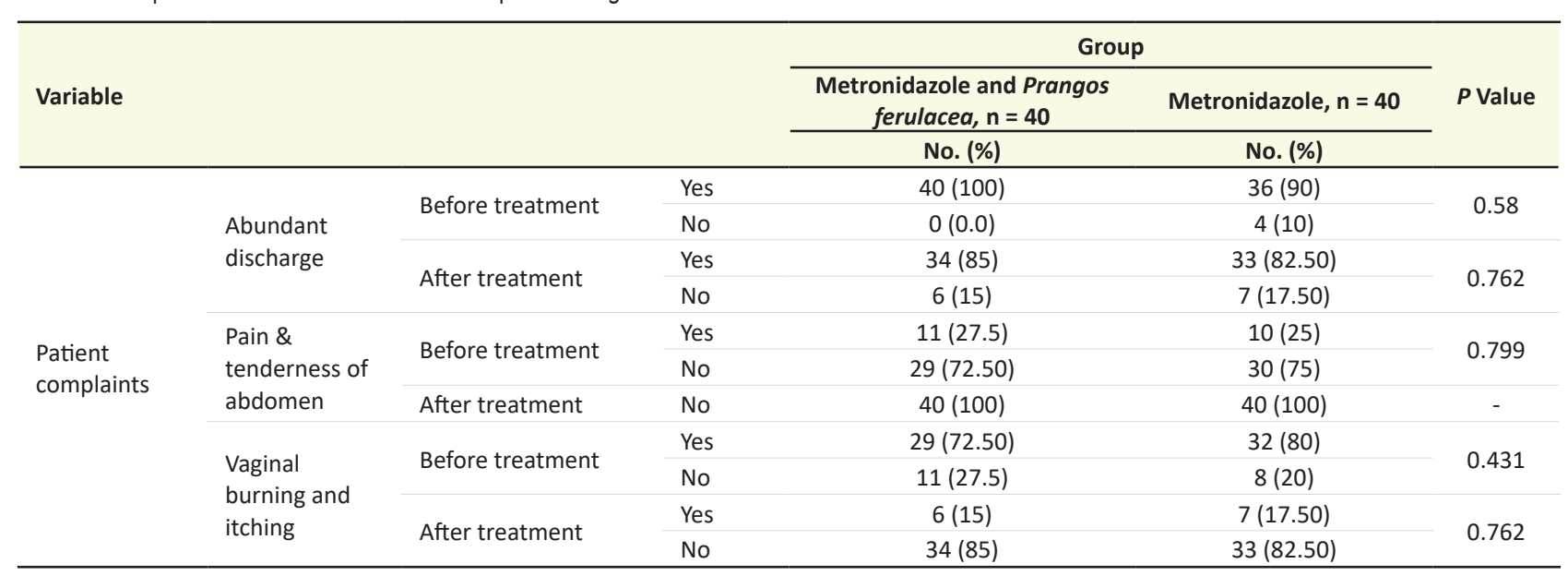

was $3.12 \pm 1.47$ in the metronidazole plus PF group and $3.97 \pm 2.13$ in the metronidazole group, which represented a significant difference $(P<0.05)$.

The examination of the side-effects of medications indicated that no patient in either group had light sensitivity, diarrhea, vaginal bleeding, or pelvic pain. Overall, 12 patients in the PF and 16 patients in the metronidazole group experienced side-effects including the lack of appetite, nausea, vomiting, headache, metallic taste in the mouth, and stomach pain. Metallic taste in the mouth, nausea, and stomach pain were the most frequent side-effects in the metronidazole group while metallic taste in the mouth was the most frequent one in the PF group. The Chi-squared test did not show any significant difference between the groups in terms of the side-effects (Table 7).

\section{Discussion}

The results of the present study showed that oral metronidazole plus PF vaginal cream, as well as oral metronidazole alone highly affected the treatment of TVI. No patient in the oral metronidazole plus PF group had abdominal tenderness and pain after treatment. T. vaginalis is an extracellular parasite which does not enter host cells. In addition, trichomonas bonds to the epithelial cell, leading to the cytolysis of epithelial lining, the phagocytosis of bacteria, vaginal epithelial cells, and erythrocytes. Further, it is absorbed by macrophages and uses carbohydrates as its main source of energy through fermentation in aerobic and anaerobic conditions, which can explain the probable role of protease in its pathogenesis. The colonization of cervicovaginal epithelial cells and cysteine proteases which destroy the extracellular protein matrix, as well as vaginitis, cervicitis, urethritis, burning and itching, and dyspareunia are all because trichomonas contains proteins to bond to the epithelial cells. Moreover, the propagation of these proteases destroys immunoglobulins which can change the immune response of the host to the infection. The production of extracellular protease via T. vaginalis may be a potential viral agent by changing or inactivating 
Table 5. Comparison of Clinical Criteria and Microscopic Criteria in 2 Treatment Groups (Before and After the Treatment)

\begin{tabular}{|c|c|c|c|c|c|c|}
\hline \multirow{3}{*}{ Variable } & & & \multicolumn{4}{|c|}{ Group } \\
\hline & & & & $\begin{array}{l}\text { Metronidazole and Prangos } \\
\text { ferulacea, } \mathrm{n}=40\end{array}$ & $\begin{array}{c}\text { Metronidazole, } \\
\mathrm{n}=\mathbf{4 0}\end{array}$ & $P$ \\
\hline & & & & No. (\%) & No. (\%) & \\
\hline \multirow{15}{*}{$\begin{array}{l}\text { Clinical } \\
\text { criteria }\end{array}$} & \multirow{4}{*}{$\begin{array}{l}\text { Foamy discharge Greenish } \\
\text { yellow }\end{array}$} & \multirow{2}{*}{ Before treatment } & Yes & $36(90)$ & $34(85)$ & \multirow{2}{*}{0.499} \\
\hline & & & No & $4(10)$ & $6(15)$ & \\
\hline & & \multirow{2}{*}{ After treatment } & Yes & $5(12.5)$ & $4(10)$ & \multirow{2}{*}{0.723} \\
\hline & & & No & $35(87.5)$ & $36(90)$ & \\
\hline & \multirow{4}{*}{ Strawberry cervix } & \multirow{2}{*}{ Before treatment } & Yes & $17(42.5)$ & $20(50)$ & \multirow{2}{*}{0.501} \\
\hline & & & No & $23(57.5)$ & $20(50)$ & \\
\hline & & \multirow{2}{*}{ After treatment } & Yes & $6(15)$ & 7 (17.5) & \multirow{2}{*}{0.724} \\
\hline & & & No & $34(85)$ & $33(82.5)$ & \\
\hline & \multirow{3}{*}{$\mathrm{pH}>4.5$} & Before treatment & Yes & $80(100)$ & $80(100)$ & 1.000 \\
\hline & & \multirow{2}{*}{ After treatment } & Yes & $6(15)$ & $7(17.50)$ & \multirow{2}{*}{0.762} \\
\hline & & & No & $34(85)$ & $6(15)$ & \\
\hline & \multirow{4}{*}{ Whiff test positive } & \multirow{2}{*}{ Before treatment } & Yes & $17(42.5)$ & $15(37.5)$ & \multirow{2}{*}{0.648} \\
\hline & & & No & $23(57.5)$ & $25(62.5)$ & \\
\hline & & \multirow{2}{*}{ After treatment } & Yes & $5(12.5)$ & $9(22.5)$ & \multirow{2}{*}{0.239} \\
\hline & & & No & $35(87.5)$ & $31(77.5)$ & \\
\hline \multirow{6}{*}{$\begin{array}{l}\text { Microscopic } \\
\text { examination }\end{array}$} & \multirow{3}{*}{$\begin{array}{l}\text { (Moving trophozoite) } \\
\text { microscopic wet test }(\times 40)\end{array}$} & Before treatment & Yes & $40(100)$ & $40(100)$ & 1.000 \\
\hline & & \multirow{2}{*}{ After treatment } & Yes & $6(15)$ & $8(20)$ & \multirow{2}{*}{0.346} \\
\hline & & & No & $34(85)$ & $32(80)$ & \\
\hline & \multirow{3}{*}{$\begin{array}{l}\text { Polymorphonuclear } \\
\text { leukocytes }(\times 100)\end{array}$} & Before treatment & Yes & $40(100)$ & $40(100)$ & 1.000 \\
\hline & & \multirow{2}{*}{ After treatment } & Yes & $6(15)$ & $8(20)$ & \multirow{2}{*}{0.346} \\
\hline & & & No & $34(85)$ & $32(80)$ & \\
\hline
\end{tabular}

Table 6. Comparison of the Frequency Distribution of the Studied Units According to Patient Complaints, Clinical Criteria, and Microscopic Criteria in the 2 Groups of Prangos ferulacea and Metronidazole (Before and After Treatment)

\begin{tabular}{|c|c|c|c|c|c|c|c|}
\hline \multirow{4}{*}{ Variable } & & \multicolumn{6}{|c|}{ Group } \\
\hline & & \multicolumn{3}{|c|}{$\begin{array}{c}\text { Metronidazole and Prangos } \\
\text { ferulacea }(n=40)\end{array}$} & \multicolumn{3}{|c|}{ Metronidazole $(n=40)$} \\
\hline & & $\begin{array}{l}\text { Before } \\
\text { Treatment }\end{array}$ & $\begin{array}{c}\text { After } \\
\text { Treatment }\end{array}$ & $P$ Value $^{\mathrm{a}}$ & $\begin{array}{l}\text { Before } \\
\text { Treatment }\end{array}$ & $\begin{array}{c}\text { After } \\
\text { Treatment }\end{array}$ & P Value \\
\hline & & No. (\%) & No. (\%) & & No. (\%) & No. (\%) & \\
\hline \multirow{4}{*}{$\begin{array}{l}\text { Patient } \\
\text { complaints }\end{array}$} & Abundant discharge & $36(90)$ & $6(15)$ & \multirow{3}{*}{$<0.001$} & $36(90)$ & $7(17.50)$ & $<0.001$ \\
\hline & Pain and tenderness of abdomen & $10(25)$ & 0 & & $11(27.50)$ & 0 & $<0.001$ \\
\hline & Burning and itching of the vagina & $32(80)$ & $7(17.50)$ & & $29(72.50)$ & $6(15)$ & $<0.001$ \\
\hline & $\mathrm{pH}>4.5$ & $40(100)$ & $6(15)$ & $<0.001$ & $40(100)$ & $7(17.50)$ & $<0.001$ \\
\hline \multirow{4}{*}{$\begin{array}{l}\text { Clinical } \\
\text { criteria }\end{array}$} & Strawberry cervix & $20(50)$ & $7(17.50)$ & \multirow{4}{*}{$<0.001$} & $17(42.50)$ & $6(15)$ & $<0.001$ \\
\hline & Foamy discharge Greenish yellow & $34(85)$ & $4(10)$ & & $36(90)$ & $5(12.50)$ & $<0.001$ \\
\hline & Whiff test positive & $15(37.5)$ & $9(22.50)$ & & $17(42.50)$ & $5(12.50)$ & $<0.001$ \\
\hline & $\mathrm{pH} \geq 4.5$ & $40(100)$ & $7(17.50)$ & & $40(100)$ & $6(15)$ & $<0.001$ \\
\hline \multirow{2}{*}{$\begin{array}{l}\text { Microscopic } \\
\text { examination }\end{array}$} & (Moving trophozoite) microscopic wet test $(\times 40)$ & $40(100)$ & $8(20)$ & \multirow{2}{*}{$<0.001$} & $40(100)$ & $6(15)$ & $<0.001$ \\
\hline & Polymorphonuclear leukocytes $(\times 100)$ & $40(100)$ & $8(20)$ & & $40(100)$ & $6(15)$ & $<0.001$ \\
\hline
\end{tabular}

a McNemar test.

different types of proteins in the cells of the host (1, 13). Additionally, hemolysis may be important in the production of nutrients from lysed erythrocytes because Trichomonas is often exacerbated after menstruation (14).

Risk factors such as the behavior, age, along with the level of education of an individual infection and other sexually transmitted infections increase the risk of TVI (15). Sexually transmitted diseases are among the 10 leading causes of diseases in young adults in the world
(16). In this study, a higher frequency of $T$. vaginalis was observed in patients in the age group between 18 and 39 years. Similarly, in a study conducted in the State of Ceará, northeastern Brazil, there was a higher positive rate in patients in the age group between 20 and 29 years (17). In a review of 30 studies on the prevalence of trichomoniasis, the mean age of 24.5-26 years was found in Iranian women. The higher incidence in younger age groups may be related to sexual behavior, the lack of awareness 
Table 7. Frequency Distribution of the Participants by the Type of Drug Side Effects in Both Groups and Metronidazole Prangos ferulacea

\begin{tabular}{lcc}
\hline & \multicolumn{2}{c}{ Group } \\
\cline { 2 - 3 } Complications & $\begin{array}{c}\text { Metronidazole and } \\
\text { Prangos ferulacea }\end{array}$ & Metronidazole \\
\cline { 2 - 3 } & No. (\%) & No. (\%) \\
\hline Anorexia & 2 & 2 \\
Mouth metal taste & 7 & 10 \\
Headache & 4 & 8 \\
Nausea & 8 & 9 \\
Vomiting & 3 & 3 \\
Stomach ache & 4 & 9 \\
Total & 12 & 16 \\
\hline
\end{tabular}

regarding sexually transmitted diseases in addition to the changes of the vaginal microbiota, especially during the menstrual period. This leads to decreased glycogen production, $\mathrm{pH}$ changes, hormonal fluctuations, and the desquamation of the epithelial tissue, favoring the installation and multiplication of the protozoa in younger patients (18). Regarding the education levels, a study conducted in Uberlândia, State of Minas Gerais, reported a higher prevalence of infection in less educated women (18). Similarly, when analyzing Portuguese women, a high frequency of $T$. vaginalis $(72.7 \%)$ was detected in those who reported only the elementary education, showing an inverse correlation between the education level and positivity for these protozoa (19).

All non-pregnant women diagnosed with Trichomonas require treatment even if they are asymptomatic. If they are left untreated, they still pass on the infection to their sexual partners. More precisely, one-third of asymptomatic women develop symptoms within 6 months (20).

Based on the findings, $92.50 \%, 86.25 \%$, and $85 \%$ of responses to treatment with oral metronidazole plus PF (Jashir in Iran) vaginal cream were based on patient complaints, clinical criteria (i.e., strawberry cervix, foamy greenish-yellow vaginal discharge, $\mathrm{pH}>4.5$, and positive amine test), and the microscopic criteria of wet mount $(\times 40)$ and polymorphonuclear leukocytes $(\times 100)$, respectively.

In addition, response to treatment with oral metronidazole and placebo vaginal cream was $91.25 \%$, $83.12 \%$, and $80 \%$ based on a patient complaint, clinical criteria, and microscopic criteria, respectively. A significant difference was found before and after the treatment in each group.

For about four decades, metronidazole has been the treatment of choice for trichomonas. Further, metronidazole is an anti-protozoa nitroimidazole with an undesirable mechanism of effect, but the gold standard for trichomonas treatment (21). It has a strong anti-microbial activity against anaerobics. Furthermore, oral treatment is preferred because the systemic use of a higher level of medication in the internal reproductive organ leads to the relapse of Trichomonas infection. The level of vaginal treatment with metronidazole is less than $50 \%$, significantly less than oral treatment. Thus, vaginal metronidazole is not recommended (22). Trichomonas treatment requires $1 \mathrm{~g}$ of single-dose oral tinidazole or metronidazole (i.e., four $500 \mathrm{mg}$ tablets) or $500 \mathrm{mg}$ every 12 hours for 5-7 days (4). The effect of tinidazole is equal to that of metronidazole, but it is more easily tolerated. Moreover, tinidazole generally decreases digestive side-effects, but it costs more than metronidazole. Studies usually report the level of treatment with these two medications as $90 \%$ to $95 \%$, respectively. The long period of treatment with metronidazole may impose rapid changes on human microbial flora due to the high level of the antibiotic. In cases of no response to treatment with metronidazole or nitroimidazole at the dose of $500 \mathrm{mg}$ every 12 hours, a single dose of $1 \mathrm{~g}$ or 5 days of treatment with $2 \mathrm{~g}$ is recommended with the effectiveness of $81 \%$ to $88 \%$. The prescription of nimorazole, ornidazole, niridazole, furazolidone, and hamixin has little effectiveness (20). In a clinical trial, 60 women were examined, which included three stages of pre-treatment, treatment, and post-treatment. The group receiving secnidazole, a metronidazole derivative, showed a $96.6 \%$ response and the group receiving Mentha crispa demonstrated a $90 \%$ response to treatment and no difference was observed between the two groups. The side-effects were $66.6 \%$ in the secnidazole group, which was $20 \%$ higher in this group compared to the Mentha crispa group (mostly nausea and a metallic taste in the mouth), indicating a significant difference. The results showed that Mentha crispa (dried mint) is effective and safe and acts as an alternative for the treatment of TVI in women (23).

The most prevalent systemic side-effects of oral metronidazole include digestive complications such as nausea, vomiting, the loss of appetite, diarrhea, abdominal cramps, constipation, glossitis, and mouth inflammation (24).

With a long history of using traditional medications and medicinal herbs for treatment, Iran has a different condition. Herbal medications as natural substances are considered as safe, inexpensive, and easily available alternatives to synthetic medications in the treatment of bacterial infection. Additionally, these medications are either effective or have no effect thus their side-effects must be closely monitored. Based on the findings of the present study and those of other studies regarding the side-effects of oral and topical metronidazole, the vaginal PF cream had no additional side-effects compared to metronidazole and even accelerated the full recovery in the treatment of TVI compared to oral metronidazole alone.

Although PF medicinal properties are confirmed, to the best of our knowledge, no clinical trial has focused on its use for humans in Iran or elsewhere. Aluminum, iron, potassium, manganese, sodium, phosphorus, and zinc are the main minerals in PF (25), which is a rich source of 
antioxidants and has further antioxidant and protective effects compared to vitamin E (26).

In addition, the presence of phenolic compounds in PF confirms its strong anti-oxidant properties. The medicinal properties of $\mathrm{PF}$ are due to the presence of monoterpenes, sescoueteterin, coumarin, flavonoid, tannin, and salpounin (27) and phenolic properties have considerable antiviral properties. Coumarin has antiviral and antihepatitis B effects. PF also has antiviral and antiHIV properties, along with inhibitory effects on the release of cytokines.

Its root extract is anti-viral which may be due to compounds such as psoralen, oxypecedanin hydrate, osthole, isoimperatorin, and gosferol. Additionally, it has cytotoxic and anti-viral effects probably by inactivating virus DNA polymerase. Similarly, PF extract has antimicrobial properties against gram-positive Staphylococcus epidermidis and Staphylococcus aureus, as well as Salmonella typhi, gram-negative bacteria, Shigella, and E. coli. Nonetheless, this plant has moderate antimicrobial properties in Staphylococcus saprophyticus (28). In addition to these properties, its flower and leaves are effective on Bacillus cereus and gram-negative bacteria, respectively (29).

Moreover, its fruit has antibacterial properties due to compounds such as a-humulene, $\alpha$-pinene, and limonin. The anti-bacterial properties of this plant are probably due to the enzymatic inhibition of oxidized compounds or reaction with sulfhydryl groups (30). In one study, adding 20\% PF to probiotic yogurt showed that PF keeps probiotic bacteria alive (31).

Based on the reports of another study, PF has antiinflammatory, analgesic, antifungal, anti-diabetic, and therapeutic effects for the diseases of the digestive system (25).

An advantage of the present study was using the wet mount and direct observation of Trichomonas as a gold standard for the diagnosis and treatment of this infection. In addition, its novelty was in examining the antibacterial anaerobic effects of PF gum for humans which, to the best of our knowledge, is the first of its kind. However, there were also limitations to this study, including a failure to follow patients experiencing a relapse, as well as the use of oral metronidazole for both groups. The results showed that the treatment group recovered faster than the control group. However, further studies are required for the use of $\mathrm{PF}$ as an alternative drug.

\section{Conclusions}

In general, the $P$. ferulacea gum vaginal cream accelerates the recovery of patients with $T$. vaginalis infection based on clinical and microscopic criteria, as well as reduced patient complaints. Thus, it can be applied as an effective treatment, along with oral metronidazole in cases of resistance to treatment or in those who prefer to use herbal medications. Nevertheless, further studies are required before its acceptance as a treatment in the absence of metronidazole.

\section{Conflict of Interests}

Authors declare that they have no conflict of interests.

\section{Ethical Issues}

The study was conducted after the approval of the Ethics Committee of Shahid Beheshti University of Medical Sciences (IR.SBMU. REC.1397.018) and registration in the Iranian Registry of Clinical Trials (identifier: IRCT20160423027534N2).

\section{Financial Support}

This study was supported by Shahid Beheshti University of Medical Sciences.

\section{Acknowledgments}

The authors express their gratitude to participants.

\section{References}

1. Mahon CR, Lehman DC. Textbook of Diagnostic Microbiology. 6th ed. St. Louis: Saunders Elsevier; 2018.

2. Miller JM, Binnicker MJ, Campbell S, et al. A guide to utilization of the microbiology laboratory for diagnosis of infectious diseases: 2018 update by the Infectious Diseases Society of America and the American Society for Microbiology. Clin Infect Dis. 2018;67(6):813-816. doi:10.1093/cid/ciy584

3. Mavedzenge SN, Pol BV, Cheng H, et al. Epidemiological synergy of Trichomonas vaginalis and HIV in Zimbabwean and South African women. Sex Transm Dis. 2010;37(7):460466. doi:10.1097/OLQ.0b013e3181cfcc4b

4. Sherrard J, Wilson J, Donders G, Mendling W, Jensen JS. 2018 European (IUSTI/WHO) International Union against sexually transmitted infections (IUSTI) World Health Organisation (WHO) guideline on the management of vaginal discharge. Int J STD AIDS. 2018;29(13):1258-1272. doi:10.1177/0956462418785451

5. Khalili Dehkordi B, Rafieian M, Hejazi SH, Yusefi HA, Yektaian N, Shirani-Bidabadi L. Effect of Achillea millefolium, Artemisia absinthium \& Juglans regia leaves extracts on Trichomonas vaginalis, in vitra. Journal of Shahrekord Uuniversity of Medical Sciences. 2011;12(4):6269. [Persian].

6. Schwebke JR, Marrazzo J, Beelen AP, Sobel JD. A phase 3, multicenter, randomized, double-blind, vehicle-controlled study evaluating the safety and efficacy of metronidazole vaginal gel $1.3 \%$ in the treatment of bacterial vaginosis. Sex Transm Dis. 2015;42(7):376-381. doi:10.1097/ olq.0000000000000300

7. Samsam Shariat H, Moatar F. Theraphy with Herbs. Tehran, Iran: Diba Publication; 2005.

8. Tada Y, Shikishima Y, Takaishi Y, et al. Coumarins and gamma-pyrone derivatives from Prangos pabularia: antibacterial activity and inhibition of cytokine release. Phytochemistry. 2002;59(6):649-654. doi:10.1016/s00319422(02)00023-7

9. Kazerooni T, Mousavizadeh K, Abdollahee A, Sarkarian 
M, Sattar A. Abortifacient effect of Prangos ferulacia on pregnant rats. Contraception. 2006;73(5):554-556. doi:10.1016/j.contraception.2005.11.001

10. Ozcan MM, Dursun N, Arslan D. Some nutritional properties of Prangos ferulacea (L.) Lindl and Rheum ribes L. stems growing wild in Turkey. Int J Food Sci Nutr. 2007;58(2):162-167. doi:10.1080/09637480601154145

11. Zargaran A, Zarshenas MM, Karimi A, Yarmohammadi H, Borhani-Haghighi A. Management of stroke as described by Ibn Sina (Avicenna) in the Canon of Medicine. Int J Cardiol. 2013;169(4):233-237. doi:10.1016/j.ijcard.2013.08.115

12. Lazenby GB, Soper DE, Nolte FS. Correlation of leukorrhea and Trichomonas vaginalis infection. J Clin Microbiol. 2013;51(7):2323-2327. doi:10.1128/jcm.00416-13

13. Ryan CM, de Miguel N, Johnson PJ. Trichomonas vaginalis: current understanding of host-parasite interactions. Essays Biochem. 2011;51:161-175. doi:10.1042/bse0510161

14. Kissinger P. Trichomonas vaginalis: a review of epidemiologic, clinical and treatment issues. BMC Infect Dis. 2015;15:307. doi:10.1186/s12879-015-1055-0

15. Ambrozio CL, Nagel AS, Jeske S, Bragança GCM, Borsuk S, Villela MM. Trichomonas vaginalis prevalence and risk factors for women in Southern Brazil. Rev Inst Med Trop São Paulo. 2016;58:61. doi:10.1590/S1678-9946201658061

16. Siracusano S, Silvestri T, Casotto D. Sexually transmitted diseases: epidemiological and clinical aspects in adults. Urologia. 2014;81(4):200-208. doi:10.5301/uro.5000101

17. Oliveira FA, Pfleger V, Lang K, et al. Sexually transmitted infections, bacterial vaginosis, and candidiasis in women of reproductive age in rural Northeast Brazil: a populationbased study. Mem Inst Oswaldo Cruz. 2007;102(6):751756. doi:10.1590/s0074-02762007000600015

18. Almeida MS, Argôlo DS, Almeida Júnior JS, Pinheiro MS, de Brito AMG. Tricomoníase: prevalência no gênero feminino em Sergipe no biênio 2004-2005. Cien Saude Colet. 2010;15 Suppl 1:1417-1421. doi:10.1590/S141381232010000700052

19. Alves MJ, Oliveira R, Balteiro J, Cruz A. Epidemiologia de Trichomonas vaginalis em mulheres. Rev Port Saúde Pública. 2011;29(1):27-34. doi:10.1016/S0870-9025(11)70005-0

20. Trichomoniasis. UpToDate website. https://www.uptodate. com/contents/trichomoniasis. 2018.

21. CDC. 2015 Sexually Transmitted Diseases Treatment Guidelines-Diseases Characterized by 1114 Vaginal Discharge. Centres for Disease Control and Prevention,
Atlanta, GA, USA; 2015. https://www.cdc.gov/mmwr/ index.html.

22. Scott HM, Klausner JD. Sexually transmitted infections and pre-exposure prophylaxis: challenges and opportunities among men who have sex with men in the US. AIDS Res Ther. 2016;13:5. doi:10.1186/s12981-016-0089-8

23. Moraes ME, Cunha GH, Bezerra MM, et al. Efficacy of the Mentha crispa in the treatment of women with Trichomonas vaginalis infection. Arch Gynecol Obstet. 2012;286(1):125130. doi:10.1007/s00404-012-2251-4

24. Mahon CR, Lehman DC, Manuselis G. Textbook of Diagnostic Microbiology. 5th ed. St. Louis: Saunders Elsevier; 2015.

25. Ozcan MM, Dursun N, Arslan D. Some nutritional properties of Prangos ferulacea (L.) Lindl and Rheum ribes L. stems growing wild in Turkey. Int J Food Sci Nutr. 2007;58(2):162-167. doi:10.1080/09637480601154145

26. Emamghoreishi M, Taghavi A, Javidnia K. The effect of aqueous and methanolic extracts of Prangos ferulacea on formalin-induced pain in mice. Journal of Jahrom University of Medical Sciences. 2012;9(4):1-6. doi:10.29252/ jmj.9.4.1

27. Kafash Farkhad N, Farokhi F, Tukmacki A, Soltani Band K. Hydro-alcoholic extract of the root of Prangos ferulacea (L.) Lindl can improve serum glucose and lipids in alloxaninduced diabetic rats. Avicenna J Phytomed. 2012;2(4):179187.

28. Golmohammadlou S, Behroozi-Lak T, Jafari R, Oshnui S, Pashapoor S. Prevalence of bacterial vaginosis during pregnancy and related factors in Urmia district. The Journal of Urmia University of Medical Sciences. 2013;24(5):347354. [Persian].

29. Amiri H. Essential oil variation of Prangos ferulacea Lindl. in different stage of plant growth. Iranian Journal of Medicinal and Aromatic Plants Research. 2007;23(1):121127. [Persian].

30. Razavi SM, Zahri S, Nazemiyeh H, Zarrini G, Mohammadi S, Abolghassemi-Fakhri MA. A furanocoumarin from Prangos uloptera roots, biological effects. Nat Prod Res. 2009;23(16):1522-1527. doi:10.1080/14786410802691909

31. Masihinezhad A, Javadi M, Barikani A, Mazloomi SM, Qajarbeigi P. Impact of Prangos ferulacea on some microbial, physicochemical and sensory properties of probiotic low fat yogurt containing lactobacillus casei. Journal of Health Sciences and Surveillance System. 2014;2(4):158-163.

(C) 2020 The Author(s); This is an open-access article distributed under the terms of the Creative Commons Attribution License (http:// creativecommons.org/licenses/by/4.0), which permits unrestricted use, distribution, and reproduction in any medium, provided the original work is properly cited. 